\title{
Effect of Delapril/Manidipine vs Olmesartan/ Hydrochlorothiazide Combination on Insulin Sensitivity and Fibrinogen in Obese Hypertensive Patients
}

\author{
Roberto Fogari, Giuseppe Derosa, Annalisa Zoppi, Pierangelo Lazzari, Luca Corradi, \\ Paola Preti and Amedeo Mugellini
}

\begin{abstract}
Objective To compare the effect of delapril/manidipine vs olmesartan/hydrochlorothiazide (HCTZ) combination on insulin sensitivity and plasma fibrinogen in obese hypertensive patients.

Patients and Methods After a 4-week placebo period, 88 obese, hypertensive (DBP $>95$ and $<110 \mathrm{mmHg}$ ) outpatients were randomized to delapril $30 \mathrm{mg} /$ manidipine $10 \mathrm{mg}$ combination or to olmesartan $20 \mathrm{mg} / \mathrm{HCTZ}$ $12.5 \mathrm{mg}$ combination for 24 weeks according to a prospective, randomized, open-label, blinded endpoint, parallel group design. At the end of the placebo period and treatment period, clinical BP, fasting plasma glucose (FPG), plasma insulin, insulin sensitivity (by euglycemic hyperinsulinemic clamp) and plasma fibrinogen were evaluated. Insulin sensitivity was expressed as the amount of glucose infused during the last 30 minutes (glucose infusion rate, GIR) in $\mathrm{mg} / \mathrm{Kg} / \mathrm{min}$. The total glucose requirement (TGR) to maintain a steady-state blood glucose level in response to a defined increase in plasma insulin concentration was also evaluated.

Results Both combinations significantly reduced SBP/DBP values $(-22.3 / 16.4 \mathrm{mmHg}$ and $-22.6 / 17.2$ $\mathrm{mmHg}$, respectively, all $\mathrm{p}<0.001 \mathrm{vs}$ placebo). GIR was significantly increased only by delapril/manidipine $(+3.01 \mathrm{mg} / \mathrm{min} / \mathrm{Kg}, \mathrm{p}=0.038 \mathrm{vs}$ placebo $)$, the difference between treatments being significant $(\mathrm{p}<0.05)$. TGR was significantly increased by delapril/manidipine $(+9.7 \mathrm{~g}, \mathrm{p}=0.034)$, while it was unaffected by olmesartan/ HCTZ. Plasma insulin as well as fibrinogen were significantly reduced by delapril/manidipine $(-17.8 \mathrm{pmol} / \mathrm{l}$, $\mathrm{p}=0.047$ and $-67.5 \mathrm{mg} / \mathrm{dl}, \mathrm{p}=0.021$, respectively), but not by olmesartan/HCTZ, the difference between the two treatments being statistically significant $(\mathrm{p}<0.05)$.

Conclusion In obese hypertensive patients the delapril/manidipine combination but not the olmesartan/ HCTZ combination significantly decreased insulin resistance and plasma fibrinogen levels, despite the similar BP lowering efficacy.
\end{abstract}

Key words: hypertension, obesity, insulin-resistance, fibrinogen, delapril/manidipine

(Inter Med 47: 361-366, 2008)

(DOI: 10.2169/internalmedicine.47.0449)

\section{Introduction}

The association between obesity and hypertension is well established: obese subjects have a 3.5-fold increased risk for developing hypertension and up to $60 \%$ of overweight or obese patients also have hypertension $(1,2)$. Insulin resis- tance with consequent hyperinsulinemia plays a pivotal role in the pathogenesis of obesity hypertension (3) and tends to cluster with glucose intolerance as well as with hemostatic and fibrinolytic disturbances, including high fibrinogen levels $(4,5)$. Endothelial dysfunction might be the pathogenetic link between these risk factors, whose clustering greatly accelerates the atherogenic process and its clinical complica-

Department of Internal Medicine and Therapeutics, Centro per l'Ipertensione e la Fisiopatologia Cardiovascolare, University of Pavia, Pavia, Italy 
tions $(6,7)$. Current hypertension treatment guidelines stress the role of total risk factor management and state the importance of not only lowering blood pressure (BP) values but also improving the global risk profile of hypertensive patients $(8,9)$. Thus optimal pharmacological treatment of obesity hypertension needs antihypertensive agents that do not exacerbate and possibly improve insulin resistance and the associated metabolic disturbances beyond lowering BP values (10-12). Furthermore, obesity is associated with the increased likelihood of not achieving goal BP: on a population basis, the probability of lack of BP control in obese hypertensives is about $50 \%$ higher than hypertensive patients who are at normal weight (13). Therefore, most obese hypertensives will require at least two antihypertensive agents to reach the BP goal of $<140 / 90 \mathrm{mmHg}$ and hypertension treatment guidelines encourage greater use of multidrug therapy especially in difficult to treat hypertension (8). Although no specific recommendation has been provided about the most effective combination antihypertensive strategy in obese hypertensives, ACE-inhibitors (ACE-I), angiotensin II receptor blockers (ARB) and calcium channel blockers (CCB), which are known to not adversely affect or even improve metabolic parameters (14-25) and diuretics, which counteract increased sodium and fluid retention and cardiac output typical or obesity hypertension (10-12), may all be suitable.

With this background the present study was undertaken to evaluate the effects on insulin sensitivity and plasma fibrinogen levels of the combination of the ACE-inhibitor delapril with the long-acting dihydropyridine calcium channel blocker manidipine as compared to the combination of the angiotensin receptor blocker olmesartan with hydrochlorothiazide in the treatment of obese hypertensive patients. We chose to test these drug combinations, at the usually recommended doses, since blockade of the renin angiotensin system with both an ACE inhibitor like delapril or an angiotensin receptor blocker like olmesartan is indicated in insulin resistant subjects like obese hypertensives. Also we wanted to verify whether adding to these agents a drug known to be metabolically neutral like manidipine or a drug known to exert potentially adverse metabolic effects like hydrochlorothiazide could differently influence insulin sensitivity and fibrinogen in these patients.

\section{Patients and Methods}

This was a prospective randomized, open-label, blinded endpoint (PROBE), parallel group study with two treatment arms.

The study population included 88 (46 men and 42 women) gender-matched obese [body mass index (BMI) $\geq$ $30 \mathrm{~kg} / \mathrm{m}^{2}$; mean weight: $88.5 \mathrm{~kg}$, range $78-112 \mathrm{~kg}$ ], non smoking outpatients, aged 43-64 years (mean age: 55 years), with mild to moderate uncomplicated essential hypertension (DBP >95 and $<110 \mathrm{mmHg}$ ). Out of 88 patients, 49 had never been previously treated for hypertension. Previously treated patients did not differ from those that were not medicated in terms of measured parameters. No gender difference in insulin sensitivity measures was observed. Patients with secondary forms of hypertension, diabetes mellitus, myocardial infarction or stroke within the previous 6 months, renal failure (serum creatinine $>1.3 \mathrm{mg} / \mathrm{dl}$ ), evidence of chronic liver disease, active peptic ulcer, pregnancy or lactation, major systemic diseases and any condition that would require the use of concomitant medication were excluded from the study. The study protocol was approved by the local Ethical Committee and written informed consent was obtained from each participant at the time of enrollment.

After an initial 4 weeks wash-out period with placebo, during which any eventual antihypertensive medication was discontinued, patients were randomly given delapril $30 \mathrm{mg} /$ manidipine $10 \mathrm{mg}$ combination o.d. or olmesartan $20 \mathrm{mg} /$ HCTZ $12.5 \mathrm{mg}$ combination o.d. for 24 weeks. From the time of enrollment until the completion of the study, each participant maintained his or her diet and usual level of physical activity and avoided a change in body weight. No concomitant medications were allowed.

At the end of the placebo and active-treatment period BP, insulin sensitivity and plasma fibrinogen were evaluated.

BP measurements were obtained from each patient (right arm) in the seated position, by using a standard mercury sphygmomanometer (Korotkoff I and V) with a cuff of appropriate size. Measurements were taken by the same doctor (not included in the study), blinded to treatment, in the morning before daily drug intake (i.e. about 24 hours after dosing) and after the subject had rested 10 minutes in a quiet room. Three successive BP readings were obtained at 1 minute intervals and averaged.

On the same day, 1 hour after the subjects had received their medication, insulin sensitivity was assessed by the euglycemic, hyperinsulinemic clamp, according to the technique of De Fronzo et al (26). At 9 a.m., after the subjects had fasted 12 hours overnight, an intravenous catheter was placed in an antecubital vein for infusion of insulin and $20 \%$ glucose. A second catheter was inserted into a brachial artery for blood sampling. A 10 minutes priming infusion of insulin (Actrapid HM, Novo Industries, Copenhagen, Denmark), calculated as the amount required to increase plasma insulin concentration to $100 \mathrm{U} / \mathrm{ml}$ during the insulin clamp, was followed by a constant infusion of $40 \mathrm{mU} / \mathrm{min} / \mathrm{m}^{2}$ of body surface area for 110 minutes. During insulin infusion, normal fasting blood glucose levels were maintained by adjustment of the infusion of a $20 \%$ glucose solution. The amount of glucose taken up (milligram per kilogram of body weight per minute) was calculated for each 10 minutes interval after the first 20 minutes of the clamp. Insulin sensitivity was calculated from the mean glucose uptake rate for the last 30 minutes of the clamp and expressed as the amount of glucose infused during that time (glucose infusion rate: GIR) in $\mathrm{mg} / \mathrm{kg} / \mathrm{min}$. The total amount of exogenous glucose required to maintain a steady-state blood glu- 
Table 1. Mean Values of the Parameters at Baseline and after Treatment with Delapril/Manidipine and Olmesartan/HCTZ.

\begin{tabular}{|l|c|c|c|c|}
\hline & \multicolumn{2}{|c|}{ Delapril/manidipine } & \multicolumn{2}{c|}{ Olmesartan/HCTZ } \\
\hline & Baseline & Treatment & Baseline & Treatment \\
\hline $\mathrm{n}(\mathrm{M} / \mathrm{F})$ & $44(24 / 20)$ & $44(24 / 20)$ & $44(22 / 22)$ & $44(22 / 22)$ \\
\hline Age $(\mathrm{y})$ & $54.9 \pm 2.6$ & - & $55.4 \pm 2.7$ & - \\
\hline BMI $\left(\mathrm{kg} / \mathrm{m}^{2}\right)$ & $33.3 \pm 0.8$ & $33.1 \pm 0.8$ & $33.5 \pm 0.9$ & $33.1 \pm 0.8$ \\
\hline $\mathrm{SBP}(\mathrm{mmHg})$ & $164.5 \pm 14.2$ & $141.2 \pm 11.3 * * *$ & $163.7 \pm 15.1$ & $140.1 \pm 11.8 * * *$ \\
\hline DBP $(\mathrm{mmHg})$ & $103.3 \pm 7.1$ & $86.9 \pm 5.8 * * *$ & $102.8 \pm 7.2$ & $85.6 \pm 5.6 * * *$ \\
\hline GIR $(\mathrm{mg} / \mathrm{min} / \mathrm{kg})$ & $4.89 \pm 0.39$ & $7.78 \pm 0.52 * *$ & $4.93 \pm 0.42$ & $4.84 \pm 0.37+$ \\
\hline TGR $(\mathrm{g})$ & $29.7 \pm 5.4$ & $39.8 \pm 5.8 * *$ & $31.1 \pm 5.9$ & $30.6 \pm 5.7+$ \\
\hline Insulin $(\mathrm{pmol} / \mathrm{L})$ & $78.4 \pm 37.2$ & $60.6 \pm 26.8 *$ & $79.8 \pm 35.6$ & $82.5 \pm 36.1$ \\
\hline Glycemia $(\mathrm{mg} / \mathrm{dL})$ & $94.4 \pm 6.4$ & $91.1 \pm 5.9$ & $93.9 \pm 6.5$ & $94.7 \pm 6.2$ \\
\hline Fibrinogen $(\mathrm{mg} / \mathrm{dL})$ & $358.9 \pm 23.5$ & $291.3 \pm 19.7 *$ & $351.3 \pm 24.9$ & $359.7 \pm 23.8$ \\
\hline TC $(\mathrm{mg} / \mathrm{dL})$ & $181.4 \pm 14.6$ & $174.7 \pm 14.7$ & $182.1 \pm 15.5$ & $188.8 \pm 14.3$ \\
\hline HDL-C $(\mathrm{mg} / \mathrm{dL})$ & $45.9 \pm 2.3$ & $46.4 \pm 2.8$ & $45.2 \pm 2.7$ & $44.7 \pm 2.2$ \\
\hline TG $(\mathrm{mg} / \mathrm{dL})$ & $134.7 \pm 35.6$ & $121.6 \pm 31.2$ & $137.8 \pm 36.8$ & $151.1 \pm 39.3$ \\
\hline
\end{tabular}

BMI: body mass index, SBP: systolic blood pressure, DBP: diastolic blood pressure, GIR: glucose infusion rate, TGR: total glucose requirement, TC: total cholesterol, HDL-C: high-density lipoprotein-cholesterol, TG: triglycerides

$* \mathrm{p}<0.05, * * \mathrm{p}<0.01, * * * \mathrm{p}<0.001$

$+\mathrm{p}<0.05$ vs delapril/manidipine

cose level in response to a defined increase in plasma insulin concentration (total glucose requirement: TGR) was also evaluated. Blood glucose in the fasting state and during glucose-clamp studies was measured by the glucose oxidase method (Beckman Auto-Analyzer; Fullerton, CA, USA). Plasma insulin concentrations were determined by radioimmunoassay (RIA).

Blood samples for evaluation of fibrinogen were drawn from an antecubital vein with minimal stasis after a 12 hours overnight fast and after N 10 minutes rest in the recumbent position. Fibrinogen levels were measured in citrated plasma samples by using a standard coagulation method (27). Fibrinogen measurements were performed in duplicate and averaged.

Metabolic parameters including total cholesterol (TC), high density lipoprotein cholesterol (HDLC) and total triglycerides (TG) as well as serum creatinine and body weight were measured at the end of the placebo and active treatment periods. Data are expressed as means \pm standard deviations. The statistical analysis of the results was performed by analysis of variance (ANOVA) for repeated measures and Spearman's rank correlation test. A p value $<0.05$ was considered statistically significant.

\section{Results}

All the 88 patients enrolled in the trial completed the study. Table 1 shows the main demographic and clinic characteristics of the two treatment groups at the end of the wash-out run-in period; there was no significant difference in gender distribution, age, BMI, BP values, TC, HDL-C, TG, fasting blood glucose, plasma insulin and fibrinogen levels. Duration of obesity-hypertension was similar in the two groups. The main results of the study are reported in
Table 2.

Both delapril/manidipine combination and olmesartan/ HCTZ combination significantly reduced SBP (by a mean of $22.3 \mathrm{mmHg}, \mathrm{p}<0.001$ vs placebo and of $22.6 \mathrm{mmHg}, \mathrm{p}<$ 0.001 vs placebo, respectively) with no statistical difference between the two treatments. HR was not significantly changed by any treatment.

During the euglycemic hyperinsulinemic clamp, plasma insulin levels increased acutely and remained at steady state plateau (mean value: $105.5 \mathrm{U} / \mathrm{ml}$ during placebo, $103.4 \mathrm{U} /$ $\mathrm{ml}$ during delapril/manidipine and $106.1 \mathrm{U} / \mathrm{ml}$ during olmesartan/HCTZ). The mean rate of glucose uptake for the last 30 minutes of the clamp (GIR), considered as an index of insulin sensitivity, was significantly increased by delapril/ manidpine combination (by a mean of $3.01 \mathrm{mg} / \mathrm{min} / \mathrm{kg}, \mathrm{p}=$ 0.038 vs placebo), but not by olmesartan/HCTZ combination $(-0.12 \mathrm{mg} / \mathrm{min} / \mathrm{kg}, \mathrm{ns})$, the difference between the two active treatments being statistically significant $(\mathrm{p}<0.05)$. The total amount of exogenous glucose required to hold glucose level constant during the clamp (TGR) was not significantly modified by olmesartan/HCTZ as compared with placebo but was significantly increased by delapril/manidipine $(+9.7$ $\mathrm{g}, \mathrm{p}=0.034$ vs placebo): plasma insulin was significantly reduced by delapril/manidipine (by a mean of $17.8 \mathrm{pmol} / \mathrm{l}, \mathrm{p}=$ 0.047 vs placebo), but not by olmesartan/HCTZ combination. Plasma fibrinogen levels were significantly reduced by delapril/manidipine combination (by a mean of $65.5 \mathrm{mg} / \mathrm{dl}$, $\mathrm{p}=0.021$ vs placebo), but not by olmesartan/HCTZ $(+4.3$ $\mathrm{mg} / \mathrm{dl}, \mathrm{ns})$, the difference between the two treatments being statistically significant $(\mathrm{p}<0.05)$. There was no significant change in body weight, BMI, fasting blood glucose, TC, HDL-C and TG during treatment with both delapril/manidipine and olmesartan/HCTZ (Table 2). 
Table 2. Mean Values of SBP, DBP, GIR, TGR, Insulin, Glycaemia, Fibrinogen, TC, HDL-C, TG and BMI during Treatment with Delapril/manidipine and Olmesartan/ HCTZ

\begin{tabular}{lcccc}
\hline & \multicolumn{2}{c}{ Delapril/manidipine } & \multicolumn{2}{c}{ Olmesartan/HCTZ } \\
\hline & Baseline & Treatment & Baseline & Treatment \\
SBP (mmHg) & $164.5 \pm 14.2$ & $141.2 \pm 11.3 * * *$ & $163.7 \pm 15.1$ & $140.1 \pm 11.8 * * *$ \\
DBP (mmHg) & $103.3 \pm 7.1$ & $86.9 \pm 5.8 * * *$ & $102.8 \pm 7.2$ & $85.6 \pm 5.6 * * *$ \\
GIR (mg/min/Kg) & $4.89 \pm 0.39$ & $7.78 \pm 0.52 * *$ & $4.93 \pm 0.42$ & $4.84 \pm 0.37+$ \\
TGR (g) & $29.7 \pm 5.4$ & $39.8 \pm 5.8 * *$ & $31.1 \pm 5.9$ & $30.6 \pm 5.7+$ \\
Insulin (pmol/L) & $78.4 \pm 37.2$ & $60.6 \pm 26.8 *$ & $79.8 \pm 35.6$ & $82.5 \pm 36.1$ \\
Glycemia (mg/dL) & $94.4 \pm 6.4$ & $91.1 \pm 5.9$ & $93.9 \pm 6.5$ & $94.7 \pm 6.2$ \\
Fibrinogen (mg/dL) & $358.9 \pm 23.5$ & $291.3 \pm 19.7 *$ & $351.3 \pm 24.9$ & $359.7 \pm 23.8$ \\
TC (mg/dL) & $181.4 \pm 14.6$ & $174.7 \pm 14.7$ & $182.1 \pm 15.5$ & $188.8 \pm 14.3$ \\
HDL-C (mg/dL) & $45.9 \pm 2.3$ & $46.4 \pm 2.8$ & $45.2 \pm 2.7$ & $44.7 \pm 2.2$ \\
TG (mg/dL) & $134.7 \pm 35.6$ & $121.6 \pm 31.2$ & $137.8 \pm 36.8$ & $151.1 \pm 39.3$ \\
BMI (Kg/m $\left.{ }^{2}\right)$ & $33.3 \pm 0.8$ & $33.1 \pm 0.8$ & $33.5 \pm 0.9$ & $33.1 \pm 0.8$ \\
\hline
\end{tabular}

GIR: glucose infusion rate, TGR: total glucose requirement, other abbreviation as in Table 1.

$* \mathrm{p}<0.05, * * \mathrm{p}<0.01, * * * \mathrm{p}<0.001$

$+\mathrm{p}<0.05$ vs delapril/manidipine

\section{Discussion}

The results of this study show that in obese patients with mild to moderate essential hypertension combination therapy with both delapril $30 \mathrm{mg}$ plus manidipine $10 \mathrm{mg}$ and olmesartan $20 \mathrm{mg}$ plus HCTZ $12.5 \mathrm{mg}$ was effective in significantly reducing SBP and DBP values, with no significant difference between the two treatments. This confirms the antihypertensive efficacy of these types of drug combination for the treatment of obesity hypertension.

The most interesting finding, however, is that, despite their equivalent BP lowering effect, delapril/manidipine combination produced a significant enhancement of insulin sensitivity and a decrease in fibrinogen concentrations whereas olmesartan/HCTZ combination did not influence insulin sensitivity nor fibrinogen levels.

The positive effect of delapril/manidipine combination on insulin sensitivity probably results from the combined action of the ACE-I and the CCB. ACE-I are well known to enhance insulin sensitivity $(14-16,18,19)$ and have been demonstrated to decrease the risk for type 2 diabetes development (28-30). Mechanisms by which ACE-I improve insulin sensitivity include: a) blockade of Ang II induced vasoconstriction with consequent vasodilation and increased delivery of insulin and glucose to skeletal muscle $(28,29)$; b) reduced degradation of bradykinin, which exerts an insulinlike activity (31); the bradykinin mediated vasodilation with an increased capillary area and vascular permeability could also increase glucose and insulin delivery to tissue (32); c) increase in adiponectin and leptin levels, both of which enhance insulin sensitivity by promoting adipocyte differentiation (33); d) enhancement of the post-receptor activity of insulin (29) e) reduction in sympathetic tone via inhibition of Ang II (29); f) reduction of potentially toxic effects of Ang
II within the pancreas, such as impaired pancreatic flow, islet cell fibrosis and death, cytokine release, oxidative stress, impaired first-phase insulin release (29). CCB are known to be metabolically neutral $(23,28)$ and some studies with long-acting dihydropyridine $\mathrm{CCB}$, including manidipine, have reported that they can improve glucose tolerance and lower insulin levels $(24,25)$. Two mechanisms have been proposed for the reduction of insulin resistance that is seen with $\mathrm{CCB}(34,35)$ : first, these drugs produce vasodilation and enhance blood flow to skeletal muscle with consequent increased delivery of insulin and glucose and enhanced nonoxidative pathways of glucose utilization; secondly, CCB also improve insulin sensitivity at the cellular level by decreasing the cytosolic-free calcium concentrations.

The decreasing effect of delapril/manidipine combination on fibrinogen levels observed in the present study might be related mainly to the action of the ACE-I. While CCB have been generally reported to not significantly influence plasma fibrinogen concentrations $(17,36)$, clinical use of ACE-I has been associated with fibrinogen reduction (17-19, 37). Mechanisms for this decreasing effect are unclear: inhibition of some steps of the regulatory mechanisms which control the hepatic synthesis of fibrinogen with possible involvement of the kallikrein-kinin system has been suggested. Due to the relationships between insulin resistance and hemostatic and fibrinolytic disturbances, the variations of plasma fibrinogen concentrations might also be related to the ACE-I induced improvement in insulin sensitivity. Since no change in lipid parameters and BMI was observed during treatment with the delapril/manidipine combination, the reduction in fibrinogen concentrations seem unrelated to lipid profile or body weight modifications.

Although some controversial data have been initially reported in the literature, with some studies showing no effect on insulin resistance $(18,19,38,39)$, current opinion is that 
ARB exert positive influence on insulin sensitivity (20-22, 40-43) and are also able to reduce the risk of onset of type 2 diabetes (28-30). ARB share the same mechanisms of insulin sensitivity improvement suggested for the ACE-I, with the exclusion of bradykinin mediated effects. Therefore, the lack of effect on insulin sensitivity observed in this study with olmesartan/HCTZ combination might be due to the influence of the diuretic. Thiazides are well known to enhance insulin resistance and worsen glycemic control although the mechanisms are unclear $(40,44-46))$. Proposed mechanisms include the effect of hypokalemia on insulin secretion (potassium depletion leads to impaired insulin release and a relative increase in the secretion of proinsulin, which is less biologically active), alterations in hepatic gluconeogenesis, an increase in free fatty acids, an increase in catecholamine release and a direct toxic effect on the pancreas $(28,44,45)$. Thus, the possible negative effect of the diuretic on insulin sensitivity might have counteracted the potential beneficial effect of the ARB with a final neutral impact of the combination therapy on this parameter. Similar considerations might be valid also to explain the lack of effect of olmesartan/HCTZ combination on plasma fibrinogen concentrations. While ARB have been found to not affect (17-19) or to decrease plasma fibrinogen (47), thiazide diuretics have been reported to have no effect (17) or more frequently to increase fibrinogen concentrations (48).

From the clinical point of view, the question of whether changes in insulin sensitivity and fibrinogen levels may result in different degrees of protection from cardiovascular complications of hypertension remains unanswered to date. While waiting for specific data it seems reasonable to prefer drugs that do not worsen or even possibly improve these metabolic parameters, especially in high risk patients like obese hypertensives. In this regard delapril/manidipine combination seems to offer some advantage as compared to olmesartan/HCTZ combination.

In conclusion, with the limitation of the relatively small number of recruited patients, this study indicates that in the treatment of obese hypertensive patients, delapril/manidipine combination, but not olmesartan/HCTZ combination significantly increased insulin sensitivity and decreased plasma fibrinogen concentrations, despite the equivalent antihypertensive efficacy. Further large-scale studies are needed to confirm these results and to clarify whether the dual actions of lowering $\mathrm{BP}$ and reducing insulin resistance and fibrinogen levels might confer an advantage with regard to end-organ protection remains to be demonstrated.

\section{References}

1. Mokdad AH, Ford Es, Bowman BA, et al. Prevalence of obesity, diabetes and obesity related health risk factors. JAMA 289: 76-79, 2003.

2. Aneja A, El-Atat F, Mc Farlane SI, Sowers JR. Hypertension and obesity. Recent Prog Horm Res 59: 169-205, 2004.

3. Reaven GM, Lithell H, Landsberg L. Hypertension and associated metabolic abnormalities - The role of insulin resistance and the sympathetic nervous system. N Engl J Med 334: 374-381, 1996.

4. Landin Y, Tengborn L, Smith U. Elevated fibrinogen and plasminogen activator inhibitor (PAI-1) in hypertension are related to metabolic risk factors for cardiovascular disease. J Intern Med 227: 273-278, 1990.

5. Jeng JR, Sheu WM, Jeng CY, Huang SH, Shieh SM. Impaired fibrinolysis and insulin resistance in patients with hypertension. Am J Hypertens 9: 484-490, 1996.

6. Lijnen HR, Collen D. Endothelium in homeostasis and thrombosis. Prog Cardiovasc Dis 39: 343-350, 1997.

7. Tomiyama H, Kimura Y, Mitsushashi H, et al. Relationship between endothelial function and fibrinolysis in early hypertension. Hypertension 31: 321-327, 1998.

8. Chobanian AV, Bakris GL, Black HR, et al. The Seventh Report of the Joint National Committee on Prevention, Detection, Evaluation and Treatment of High Blood Pressure. The JNC 7 Report. JAMA 289: 2560-2572, 2003.

9. ESH-ESC Guidelines Committee. 2003 Guidelines for the management of arterial hypertension. J Hypertens 21: 1011-1053, 2003.

10. Dentali F, Sharma AM, Douketis JD. Management of hypertension in overweight and obese patients: a practical guide for clinicians. Curr Hypertens Rep 7: 330-336, 2005.

11. Doggrell SA. Clinical evidence for drug treatments in obesityassociated hypertensive patients - a discussion paper. Methods Find Exp Clin Pharmacol 27: 119-125, 2005.

12. Wenzel UO, Krebs C. Treatment of arterial hypertension in obese patients. Contrib Nephrol 151: 230-242, 2006.

13. Lloyd-Jones DM, Evans JC, Larson MG, O’Donnel CJ, Roccella EJ, Levy D. Differential control of systolic and diastolic blood pressure: factors associated with lack of blood pressure control in the community. Hypertension 36: 594-599, 2000.

14. Lithell H, Pollare $T$, Berne $C$. Insulin sensitivity in newly detected hypertensive patients: influence of captopril and other antihypertensive agents on insulin sensitivity and related biological parameters. J Cardiovasc Pharmacol 15 (Suppl 5): S46-S52, 1990.

15. Torlone E, Britta A, Rambotti AM. Improved insulin action and glycemic control after longterm angiotensin converting enzyme inhibition in subjects with arterial hypertension and type II diabetes. Diabetes Care 16: 1347-1355, 1993.

16. Falkner B, Canessa M, Anzalone D. Effect of angiotensin converting enzyme inhibitor (lisinopril) on insulin sensitivity and sodium transport in mild hypertension. Am J Hypertens 8: 454-460, 1995.

17. Fogari R, Zoppi A, Malamani GD, Marasi G, Vanasia A, Villa G. Effects of different antihypertensive drugs on plasma fibrinogen in hypertensive patients. Br J Clin Pharmacol 39: 471-476, 1995.

18. Fogari R, Zoppi A, Corradi L, Lazzari P, Mugellini A, Lusardi P. Comparative effect of lisinopril and losartan on insulin sensitivity in the treatment of non diabetic hypertensive patients. $\mathrm{Br} \mathrm{J}$ Clin Pharmacol 46: 467-471, 1998.

19. Fogari R, Zoppi A, Lazzari $P$, et al. ACE inhibition but not angiotensin II antagonism reduces plasma fibrinogen and insulin resistance in overweight hypertensive patients. J Cardiovasc Pharmacol 32: 616-620, 1998.

20. Iimura $O$, Shimamoto $K$, Matsuda $K$, et al. Effects of angiotensin receptor antagonist andangiotensin converting enzyme inhibitor on insulin sensitivity and fructose fed hypertensive rats and essential hypertensives. Am J Hypertens 8: 353-357, 1995.

21. Moan A, Hoieggen A, Nordby G, Eide IK, Kjelsen SE. Effects of losartan on insulin sensitivity in severe hypertension:connections through sympathetic nervous system activity. J Hum Hypertens 9 
(Suppl 5): S45-S50, 1995.

22. Fogari R, Derosa G, Zoppi A, et al. Comparison of the effects of valsartan and felodipine on plasma leptin and insulin sensitivita in hypertensive obese patients. Hypertens Res 28: 209-214, 2005.

23. Trost BN, Weidman P. Effects of calcium antagonists on glucose homeostasis and serum lipids in non-diabetic and diabetic subjects: a review. J Hypertens 5: S81-S104, 1987.

24. Beeer NA, Jakubowicz DJ, Beer RM, Arocha IR, Nestler JE. Effects of nitrendipine on glucose tolerance and serum insulin and dehydroepiandrosterone sulfate levels in insulin-resistant obese and hypertensive men. J Clin Endocrinol Metab 76: 178-183, 1993.

25. Ueshiba H, Miyachi Y. Effects of long-acting calcium channel blockers, amlodipine, manidipine and cilnidipine on steroid hormones and insulin resistance in hypertensive obese patients. Intern Med 43: 561-565, 2004.

26. De Fronzo RA, Tobin JA, Andres B. Glucose clamp technique, a method for quantifying insulin secretion and resistance. Am J Physiol 237: 214-223, 1979.

27. Clauss A. Rapid physiological coagulation method for the determination of fibrinogen. Acta Haematol 17: 237-246, 1957.

28. Asfaha S, Padwal R. Antihypertensive drugs and incidence of type 2 diabetes: evidence and implications for clinical practice. Curr Hypertens Rep 7: 314-322, 2005.

29. Jandeleit-Dahm KA, Tikellis C, Reid CM, Johnston CI, Cooper ME. Why blockade of the rennin-angiotensin system reduces the incidence of new-onset diabetes. J Hypertens 23: 463-473, 2005.

30. Ostergren J. Renin-angiotensin system blockade in the prevention of diabetes. Diabetes Res Clin Pract 73(Suppl 3): S13-S21, 2007.

31. Tomiyama H, Kushiro T, Abeta $H$, et al. Kinins contribute to the improvement of insulin sensitivita during treatment with angiotensin converting enzyme inhibitor. Hypertension 23: 450-455, 1994.

32. Rett K, Wicklay R, Diewtze GJ. Metabolic effects of kinins: historical and recent developments. J Cardiovasc Pharmacol 15: 1620-1628, 1990.

33. Kon V, Jabs K. Angiotensin in atherosclerosis. Curr Opin Nephrol Hypertens 13: 291-297, 2004.

34. Baron AD, Brechtel GB, Wallace P, Edelman SV. Rates and tissue sites of non-insulin and insulin-mediated glucose uptake in humans. Am J Physiol 255: E769-E774, 1988.

35. Draznin B, Sussman KE, Eckel RH, Kao M, Yost T, Sherman MA. Possible role of cytosolic free calcium in mediating insulin resistance in obesity and hyperinsulinemia. J Clin Invest 82: 1848$1852,1988$.

36. Koenig W, Sund M, Ernst E, et al. Effects of felodipine ER and hydrochlorothiazide on bloodrheology in essential hypertension-a randomized, double-blind cross-over study. J Intern Med 229: 535-538, 1991.

37. Tsagadopoulos D, Antonakoudis H, Makris T, et al. Effect of antihypertensive treatment on lipids and fibrinogen: Greek multicentre study of cilazapril. Cardiology 87: 524-528, 1996.

38. Laakso M, Karjalaainen L, Lempiainen-Kuosa P. Effects of losar$\tan$ on insulin sensitivity in hypertensive subjects. Hypertension 28: 392-396, 1996.

39. Moan A, Hoieggen A, Seljeflot I, Risanger T, Arnesen H, Kjeldsen SE. The effect of angiotensin II receptor antagonism with losartan on glucose metabolism and insulin sensitivity. J Hypertens 14: 1083-1097, 1996.

40. Grassi G, Seravalle G, Dell'Oro R, et al. Comparative effects of candesartan and hydrochlorothiazide on blood pressure, insulin sensitivity and sympathetic drive in obese hypertensive individuals: results of the CROSS study. J Hypertens 21: 1761-1769, 2003.

41. Furuhashi M, Ura N, Takizawa $\mathrm{H}$, et al. Blockade of the rennin angiotensin system decreases adipocyte size with improvement in insulin sensitivity. J Hypertens 22: 1977-1982, 2004.

42. Okada K, Hirano T, Ran J, Adachi M. Olmesartan medoxomil, an angiotensin II receptor blocker ameliorates insulin resistance and decreases triglyceride production in fructose-fed rats. Hypertens Res 27: 293-299, 2004.

43. De Vinuesa SG, Giocoechea M, Kanter J, et al. Insulin resistance, inflammatory biomarkers and adipokines in patients with chronic kidney disease: effects of angiotensin II blockade. J Am Soc Nephrol 17: S206-S212, 2006.

44. Pandit MK, Burke J, Gustafson AB, Minocha A, Peiris AN. Druginduced disorders of glucose tolerance. Ann Intern Med 118: 529539, 1993.

45. Harper R, Ennis CN, Heaney AP, et al. A comparison of the effects of low- and conventionaldose thiazide diuretic on insulin action in hypertensive patients with NIDDM. Diabetologia 38: 853$859,1995$.

46. Wofford MR, King DS, Harrel TK. Drug-induced metabolic syndrome. J Clin Hypertens 8: 114-119, 2006.

47. Rayner BL, Trinder YA, Baines D, Isaacs S, Opie LH. Effect of losartan versus candesartan on uric acid, renal function and fibrinogen in patients with hypertension and hyperuricemia associated with diuretics. Am J Hypertens 19: 208-213, 2006.

48. Khder Y, Bray des, Boscs L, El Ghawi R, et al. Calcium antagonists and thiazide diuretics have opposite effects on blood rheology and radial artery compliance in arterial hypertension: a randomized double-blind study. Fundam Clin Pharmacol 12: 457-462, 1998.

(C) 2008 The Japanese Society of Internal Medicine http://www.naika.or.jp/imindex.html 